OPEN ACCESS

\title{
A Reference Electrode for In Situ Impedance Measurements in Sodium- Ion Batteries
}

To cite this article: Fabian Linsenmann et al 2019 J. Electrochem. Soc. 166 A3668

View the article online for updates and enhancements. 


\title{
A Reference Electrode for In Situ Impedance Measurements in Sodium-Ion Batteries
}

\author{
Fabian Linsenmann, ${ }^{*}{ }^{*} \mathrm{z}$ Daniel Pritzl, ${ }^{*}$ and Hubert A. Gasteiger** \\ Chair of Technical Electrochemistry, Department of Chemistry and Catalysis Research Center, Technische Universität \\ München, 85748 Garching, Germany
}

\begin{abstract}
In this work, we introduce a newly developed micro-reference electrode ( $\mu$-RE) for sodium-ion batteries (SIBs). This $\mu$-RE is based on a $50 \mu \mathrm{m}$-sized tin-coated copper wire, manually insulated using polyurethane (PU) spray, such that only the cross-sectional area of the wire tip is in contact with the electrolyte. The tin-coating allows for facile in situ electrochemical sodiation, resulting in a stable potential of the wire that enables in situ Electrochemical Impedance Spectroscopy (EIS). We will show that reliable singleelectrode impedance data from SIB cells can be obtained with this new tin wire $\mu$-RE ( $\mu$-TWRE) concept, validated by comparing $\mu$-RE-based single-electrode impedance data with those acquired by a symmetrical cell approach. As hard carbons are currently the most promising anode material for SIBs, we evaluate the impedance evolution of a hard carbon anode over extended charge/discharge cycles in a half-cell vs. sodium metal, comparing its impedance measured at the same state-of-charge (SOC) over 50 cycles. Thus, we demonstrate that EIS using a $\mu$-TWRE can be used as a convenient tool to quantify the impedance evolution of SIB anodes and cathodes.

(C) The Author(s) 2019. Published by ECS. This is an open access article distributed under the terms of the Creative Commons Attribution 4.0 License (CC BY, http://creativecommons.org/licenses/by/4.0/), which permits unrestricted reuse of the work in any medium, provided the original work is properly cited. [DOI: $10.1149 / 2.0741915 \mathrm{jes}$ ]

Manuscript submitted September 5, 2019; revised manuscript received October 21, 2019. Published November 5, 2019. This was Paper 146 presented at the Dallas, Texas, Meeting of the Society, May 26-May 30, 2019.

The demand for lithium-ion batteries (LIBs) used in portable electronics and automotive applications has strongly increased within the last ten years. In 2018, for the first time in history, more than 2 million fully electric vehicles (FEVs) were sold worldwide. ${ }^{1}$ As recently decided by the European Union, the maximum average fleet $\mathrm{CO}_{2}$ emission target of $95 \mathrm{~g} / \mathrm{km}$ (from 2021) must be even further reduced to $\approx 60 \mathrm{~g} / \mathrm{km}$ by 2030 , which forces original equipment manufacturers (OEMs) to strongly increase their share of hybrid and fully electric vehicles (EVs). This is one reason why more and more OEMs announce the release of new electric vehicles with increasing battery pack sizes, with alone the Volkswagen group stating that they are planning to sell 22 million EVs by $2030 .^{2}$ Therefore, a rapid acceleration of the battery demand is to be expected within the next years, which will likely affect the demand for lithium and its cost. In order to become independent from lithium, cheaper and more sustainable alternatives to LIBs are getting into focus. Since sodium is $\approx 1000$ more abundant in the earth's crust and less locally concentrated compared to lithium, ${ }^{3}$ sodium-ion battery (SIB) research has attracted considerable attention in recent years. ${ }^{4-7}$ Particularly, applications such as grid storage where high volumetric and gravimetric energy density are less critical could provide an interesting use case for SIBs. ${ }^{8}$

In order to advance the fundamental materials characterization for SIBs, it is desirable to adapt the electrochemical and analytical techniques established in the field of LIB research to sodium-based systems. Electrochemical impedance spectroscopy (EIS) is a fast and non-invasive technique to provide valuable insights into intercalation kinetics, interfacial processes, and/or the effect of additives via monitoring of the associated resistances, so that it is used intensively for LIB studies. ${ }^{9-15}$ However, the measurement of cell impedance data does not allow for the deconvolution of cathode and anode impedances, and for in situ impedance analysis of individual electrodes a reference electrode (RE) is required. ${ }^{9,16-18}$ Without a RE, the only possibility to independently quantify the anode and/or cathode impedance is the disassembly of multiple cells and the recombination of identical anode or cathode pairs in symmetrical cells..$^{13,19-22}$ In the latter case, monitoring the evolution of the electrode impedance as a function of state-of-charge (SOC) and/or over extended cycling requires dis- and reassembly of numerous cells, so that artefacts due to cell opening and electrode transfer may be introduced. On the other hand, when using $\mu$-REs, the design and placement of the $\mu-\mathrm{RE}$ with respect to working

*Electrochemical Society Student Member.
**Electrochemical Society Fellow.

${ }^{\mathrm{z} E-m a i l: ~ f a b i a n . l i n s e n m a n n @ t u m . d e ~}$
(WE) and counter electrode (CE) in a three-electrode setup is crucial in order to obtain artefact-free impedance spectra. ${ }^{9,16,17,23}$ The $\mu$-RE has to fulfill the following requirements: a) its potential has to be stable within the measuring duration of the impedance spectrum (typically $<20 \mathrm{~min}$ ); b) it has to be located centrally between anode and cathode, where the electric field is homogeneous; and, c) its cross-sectional dimensions have to be small compared to the distance between the electrodes in order to minimize the potential gradient across the diameter of the $\mu$-RE. In general, it is advantageous to use $\mu$-REs with a well-defined reference potential, as simple metal wire pseudo-REs frequently exhibit too large potential drifts, as was shown by Dollé et al. for copper and silver wires $;{ }^{24}$ in some cases, however, the potential of pseudo-REs is sufficiently stable to enable EIS analysis down to frequencies of $\approx 0.1 \mathrm{~Hz} .^{14,25}$

For EIS studies in LIBs, Solchenbach et al. ${ }^{9}$ incorporated a $50 \mu \mathrm{m}$ thick insulated gold wire into a standard Swagelok T-cell, whereby the wire tip that exposes the gold to the electrolyte was located centrally between cathode and anode, separated from each electrode by a $\approx 200 \mu \mathrm{m}$ thick glass fiber separator. To obtain a stable reference potential, the gold wire tip was electrochemically lithiated in situ from a lithium source within the cell (a metallic lithium electrode or a conventional LIB cathode), producing an Li-Au alloy with a well-defined potential of $\approx 0.31 \mathrm{~V}$ vs. $\mathrm{Li}^{+} / \mathrm{Li}$. As the Au-Na phase diagram shows several intermetallic phases such as AuNa and $\mathrm{AuNa}_{3},{ }^{26}$ we were hoping that the same gold wire $\mu$-RE concept could be utilized for SIB studies. Unfortunately, tests performed in our group to electrochemically alloy gold with sodium were unsuccessful, since the intercalation kinetics of sodium in gold seem to be significantly slower compared to lithium. However, there are other metals known for facile alloying with sodium, such as barium, lead, zinc, and tin. ${ }^{27}$ Tinned copper wires are standard materials used for electrical leads and therefore can be purchased with diameters down to $25 \mu \mathrm{m}$. Abraham et al. ${ }^{18}$ successfully used an insulated $25 \mu \mathrm{m}$ thick tinned copper wire as $\mu$-RE for EIS measurements in a LIB, which was also lithiated in situ to form an $\mathrm{Li}_{x} \mathrm{Sn}$ alloy for which one expects to obtain a stable potential.

In the present study, we demonstrate that a commercially available tinned copper wire can be easily (and even reversibly) sodiated, ultimately yielding a tin wire $\mu$-RE (referred to as $\mu$-TWRE) with a relatively stable reference potential. We will show that reliable single-electrode impedance data from sodium-ion battery cells can be obtained with this new $\mu$-TWRE concept, validated by comparing $\mu$-TWRE based single-electrode impedance data with those obtained by the symmetrical cell approach. Due to their low cost and comparably good capacities, hard carbon materials are to date the almost 
ubiquitously used and most promising anodes for SIBs. ${ }^{28-31}$ Despite their central importance for SIBs, very few impedance data on sodiated hard carbon electrodes have been published and, to the best of our knowledge, there is no publication analyzing the evolution of the hard carbon impedance over extended cycling that is based on electrode-resolved EIS analysis, i.e., without being compromised by the impedance contribution from the counter electrode, such as a sodium metal electrode. Therefore, we will here track the evolution of the impedance of a hard carbon electrode in a half-cell setup over extended cycling by means of an in situ impedance measurement with a $\mu$-TWRE.

\section{Experimental}

Electrode and electrolyte preparation.-Hard Carbon electrodes were composed of hard carbon (Kuranode, BET surface area $5.2 \mathrm{~m}^{2} / \mathrm{g}$, Kuraray, Japan), sodium carboxymethyl cellulose (CMC, Sunrose, NPI, Japan), and styrene-butadiene rubber (SBR, emulsion in water, solid content $40 \mathrm{wt} \%$, Zeon, Japan) at a weight ratio of 97:1.5:1.5. Na$\mathrm{CMC}$ was first mixed with highly pure water $(18 \mathrm{M} \Omega \mathrm{cm}$, Merck Millipore, Germany) using a planetary mixer (Thinky, USA; at $2000 \mathrm{rpm}$ for $15 \mathrm{~min}$ ). Hard carbon powder was added in three steps in order to reach a final solid content of $50 \mathrm{wt} \%$ with 2 min mixing in between at $2000 \mathrm{rpm}$. SBR was added to the slurry and mixed at $500 \mathrm{rpm}$ for $2 \mathrm{~min}$. The ink was coated onto aluminum foil (MTI, United States) using a $100 \mu \mathrm{m}$ gap size four-way film applicator (Erichsen, Germany) and dried at room temperature for $5 \mathrm{~h}$, resulting in an average loading of $3 \pm 0.3 \mathrm{mg} / \mathrm{cm}^{2}$ ( $\equiv 0.87 \pm 0.087 \mathrm{mAh} / \mathrm{cm}^{2}$, based on a specific capacity of $290 \mathrm{mAh} / \mathrm{g}_{\mathrm{HC}}$ ); hard carbon electrodes were then punched out at a diameter of $11 \mathrm{~mm}$. Together with glass fiber separators $(11 \mathrm{~mm}$ diameter, VWR, Germany), the electrodes were dried under dynamic vacuum at $120^{\circ} \mathrm{C}$ for $12 \mathrm{~h}$ in a glass oven (drying oven 585, Büchi, Switzerland) and transferred into an argon-filled glove box (MBraun, Germany) without exposure to air. The as-used uncompressed hard carbon electrodes had a thickness of $59 \pm 2 \mu \mathrm{m}$ (Al current collector $15 \pm 1 \mu \mathrm{m})$ and a porosity of $\approx 60 \%$. Note that the home-made Swagelok T-cell setup is designed in a way that only a pressure of $\approx 2$ bar is exerted on the cell stack by the compression spring. By compressing a hard carbon electrode using a strain/compression testing machine (Zwick, Germany) with a defined pressure of 2 bar, the thickness change was found to be $+/-1 \mu \mathrm{m}$, which is within the error of the thickness gauge (Mitutoyo, Japan). Sodium disks (11 mm diameter, thickness $\approx 500 \mu \mathrm{m}$ ) were punched out from sodium foil that was prepared from sodium ingots ( $99.95 \%$, Sigma Aldrich) within an argon-filled glove box $\left(\mathrm{O}_{2}\right.$ and $\left.\mathrm{H}_{2} \mathrm{O}<0.1 \mathrm{ppm}\right)$. The electrolyte was prepared by mixing $50 \mathrm{vol} \%$ ethylene carbonate (EC, $\geq 99 \%$, Sigma Aldrich) and 50 vol\% dimethyl carbonate (BASF SE, Germany) with $1 \mathrm{M} \mathrm{NaPF}_{6}(99.9 \%$, Kishida Chemicals, Japan).

Cell assembly and electrochemical testing.-Swagelok T-cells were assembled inside an argon-filled glove box with hard carbon working electrodes (WE) and sodium counter electrodes (CE), $60 \mu \mathrm{L}$ electrolyte, two glass fiber separators, and a tinned copper wire (diameter $=50 \mu \mathrm{m}$, Eurowire, Great Britain) with a manually applied insulation as reference electrode ( $\mu$-TWRE). Unfortunately, as demonstrated recently by Morasch et al., ${ }^{32}$ this cell configuration would not allow for the acquisition of single-electrode EIS data by means of a $\mu-R E$, since the resistances of WE and CE have to be within the same order of magnitude when using a high-impedance $\mu$-RE (i.e., a $\mu$-TWRE or a lithiated gold wire $\mu$-RE). They showed, however, that the attachment of a freestanding high-surface area carbon electrode to a metallic lithium electrode reduces its impedance to the extent that artefact-free half-cell EIS data can be acquired with a high-impedance RE. ${ }^{32}$ Following their recommendation, we sandwiched a high-surface area carbon fiber paper (H1410 type from Freudenberg (Germany), cut to $10 \mathrm{~mm}$ diameter, with a thickness of $150 \mu \mathrm{m}$ and a BET area of $\approx 14 \mathrm{~m}^{2} / \mathrm{g}$ ) between the separator and the sodium metal CE (s. Figure 1a), which effectively reduces the impedance of the latter by means of chemical interaction of the metallic sodium with the carbon
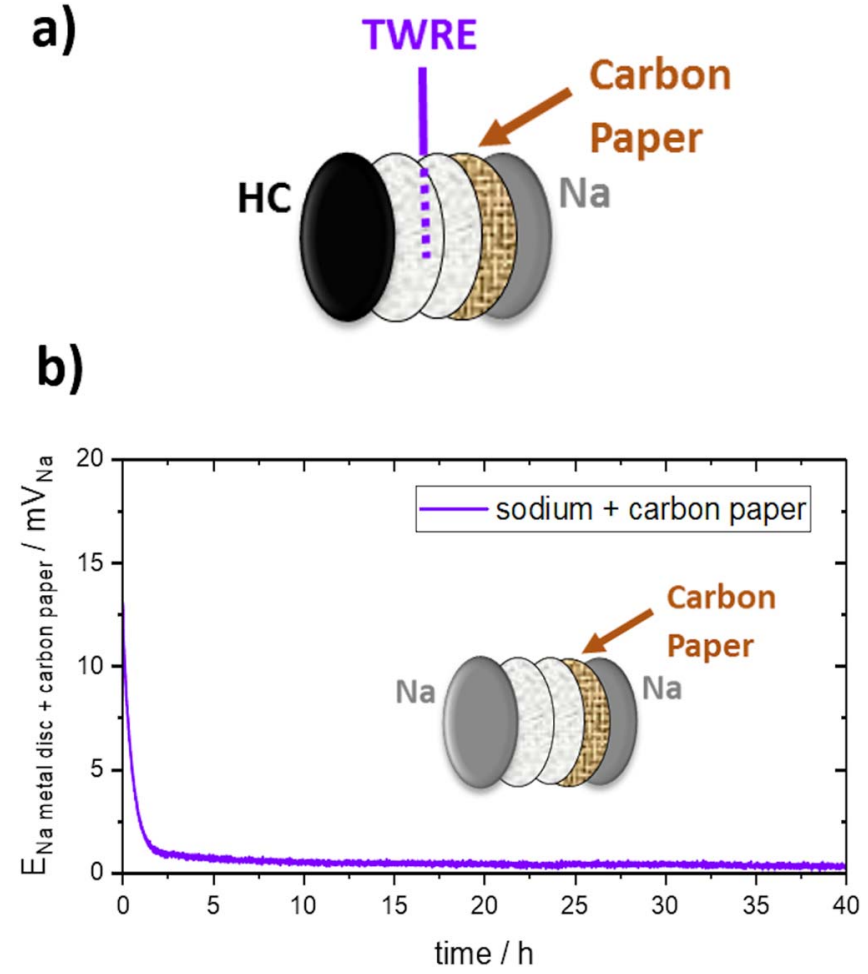

Figure 1. a) Electrode stack exemplarily shown for the in situ EIS measurement of an HC electrode in a Swagelok T-cell using a $\mu$-TWRE that is located centrally between two glass fiber separators. A carbon paper freestanding electrode is put on top of the sodium metal disk in order to decrease the resistance of the sodium $\mathrm{CE} ;{ }^{32} \mathrm{~b}$ ) mixed potential of the carbon paper/sodium composite measured at OCV vs. sodium metal.

matrix, resulting in a mixed potential of the carbon paper/sodium composite anode that is within less than $0.5 \mathrm{mV}$ of that of a pure metallic sodium electrode after $5 \mathrm{~h}$ (s. Figure $1 \mathrm{~b}$ ).

Impedance spectra analysis.-In order to compare the impedance responses measured via the $\mu$-RE with those collected using a symmetrical cell, the spectra were fitted with a MATLAB-based application ("EIS Breaker" written by J. Landesfeind), ${ }^{14}$ which applies a fminsearch MATLAB function using a Nelder-Mead simplex algorithm and modulus weighing. The underlying equivalent circuit is depicted in Figure $5 c$ and consists of a high-frequency resistance $R_{H F R}$ and a mono-rail transmission-line incorporating a pore resistance $\mathrm{R}_{\text {pore }}$ and a charge transfer resistance $R_{C T}$ in parallel to a constant phase element $\mathrm{Q}$, similar to the one used by Landesfeind et al. ${ }^{14}$ The transmission line is simplified by neglecting the resistance rail through the active material due to the high electronic conductivity of the carbon electrode and is therefore called mono-rail TLM (mTLM).

The tinned copper wire was insulated using polyurethane spray (Urethan 71, Kontakt Chemie, Germany), resulting in a total thickness of $\approx 100 \mu \mathrm{m}$ (s. Figure 2 ). The incorporation of the $\mu-\mathrm{RE}$ in the Swagelok T-cell was done according to Solchenbach et al. ${ }^{9}$

Prior to cell cycling, the $\mu$-TWRE was electrochemically sodiated in situ from the sodium CE by applying a charging current of $50 \mathrm{nA}$ until a potential cutoff of $10 \mathrm{mV}$ vs. $\mathrm{Na}^{+} / \mathrm{Na}$ is reached, requiring several tens of hours (see later). At the end of the charging process, the potential was found to relax to $\approx 110 \mathrm{mV}$ vs. $\mathrm{Na}^{+} / \mathrm{Na}$ within $5 \mathrm{~h}$ and then remained relatively stable over more than $100 \mathrm{~h}$. The hard carbon half-cells were cycled galvanostatically at $\mathrm{C} / 10$ (referenced to a hard carbon capacity of $290 \mathrm{mAh} / \mathrm{g}_{\mathrm{HC}}$ ) within a cell potential range of $+1.5 \mathrm{~V}_{\text {cell }}$ and $+10 \mathrm{mV}_{\text {cell }}$. For impedance measurements, the cell was charged at $\mathrm{C} / 10$ to $100 \mathrm{mV}_{\text {cell }}$ where it was switched to OCV for $30 \mathrm{~min}$, followed by potential-controlled EIS (referred to as 


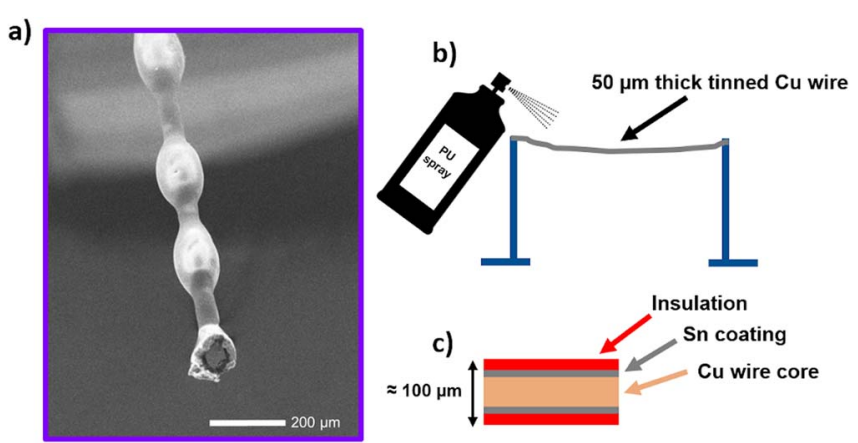

Figure 2. a) SEM image of the tinned copper wire coated with polyurethane (PU); b) insulation process of the $\mu-R E$ wire using PU spray; c) schematic representation of the $\mu$-RE consisting of a copper wire core, a Sn layer coating, and PU insulation, with a total thickness of the insulated $\mu$-TWRE of $\approx 100 \mu \mathrm{m}$.

PEIS) at OCV using the $\mu$-TWRE and a perturbation amplitude of $20 \mathrm{mV}$ between $100 \mathrm{kHz}$ and $0.1 \mathrm{~Hz}$. For validating EIS measurement results performed with the $\mu$-TWRE, the impedance response of a freshly assembled cell after ca. $24 \mathrm{~h}$ rest at OCV was compared to EIS measurements using the symmetrical cell approach. All experiments (cycling and impedance) were performed in temperature-controlled chambers (Binder, Germany) at $25^{\circ} \mathrm{C}$.

\section{Results and Discussion}

In situ sodiation of the $\mu$-TWRE.-As experimentally shown by Solchenbach et al., the use of a pseudo- $\mu$-RE (in that case a nonlithiated gold wire $\mu-R E$, s. Figure $3 b$ and $c$ in Reference 9) can lead to artefacts in the impedance spectra in the low-frequency region if the potential drift is too large relative to the perturbation amplitude. Thus, while in some instances pseudo- $\mu$-RE can be used to produce high-quality impedance spectra down to even $0.1 \mathrm{~Hz},{ }^{14,25} \mu$-REs with an electrochemically well-defined potential are preferable. For this reason, Solchenbach et al. ${ }^{9}$ had lithiated their gold wire $\mu-R E$, and we will explore the in situ sodiation of the tip of the polyurethane coated tin-shroud that surrounds the copper wire of the here presented $\mu-\mathrm{RE}$ (s. Figure 2). Figure 3 shows the potential profile during the in situ galvanostatic sodiation and desodiation of the tin phase of the $\mu$ $\mathrm{RE}$ (total diameter $\approx 100 \mu \mathrm{m}$, assembled in a Swagelok T-cell) using sodium metal disks as WE and CE. The (de)-sodiation was performed with a constant current of $50 \mathrm{nA}$, with a lower cutoff potential of $10 \mathrm{mV}$ vs. $\mathrm{Na}^{+} / \mathrm{Na}$, and an upper cutoff potential of $1.5 \mathrm{~V}$ vs. $\mathrm{Na}^{+} / \mathrm{Na}$,

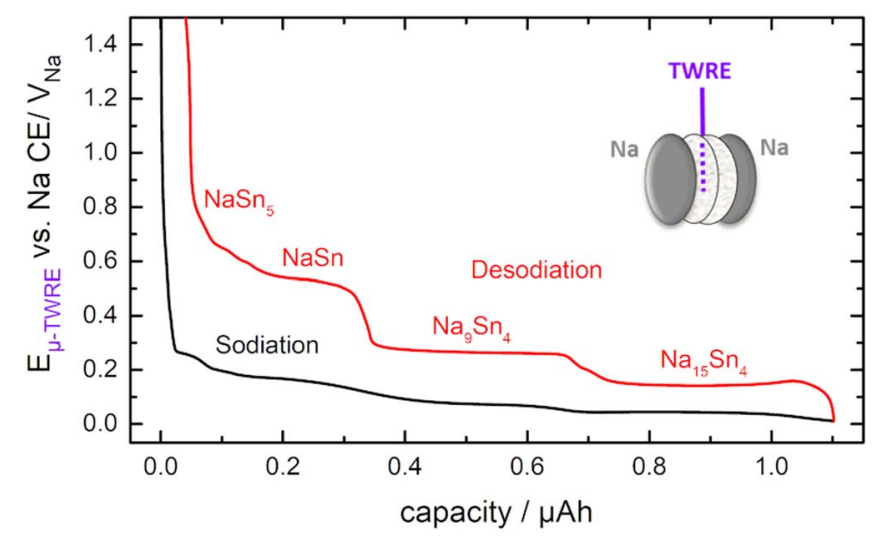

Figure 3. Potential profile during the reversible in situ (de)-sodiation of the tip of the Sn coating of the $\mu$-TWRE recorded from the sodium metal WE in a T-cell with two sodium metal electrodes (s. inset scheme). During desodiation, four potential plateaus can be distinguished, most likely assignable to $\mathrm{Na}-\mathrm{Sn}$ phases with the compositions $\mathrm{Na}_{15} \mathrm{Sn}_{4}, \mathrm{Na}_{9} \mathrm{Sn}_{4}, \mathrm{NaSn}$ and $\mathrm{NaSn}_{5}$ according to Ellis et al. ${ }^{33}$

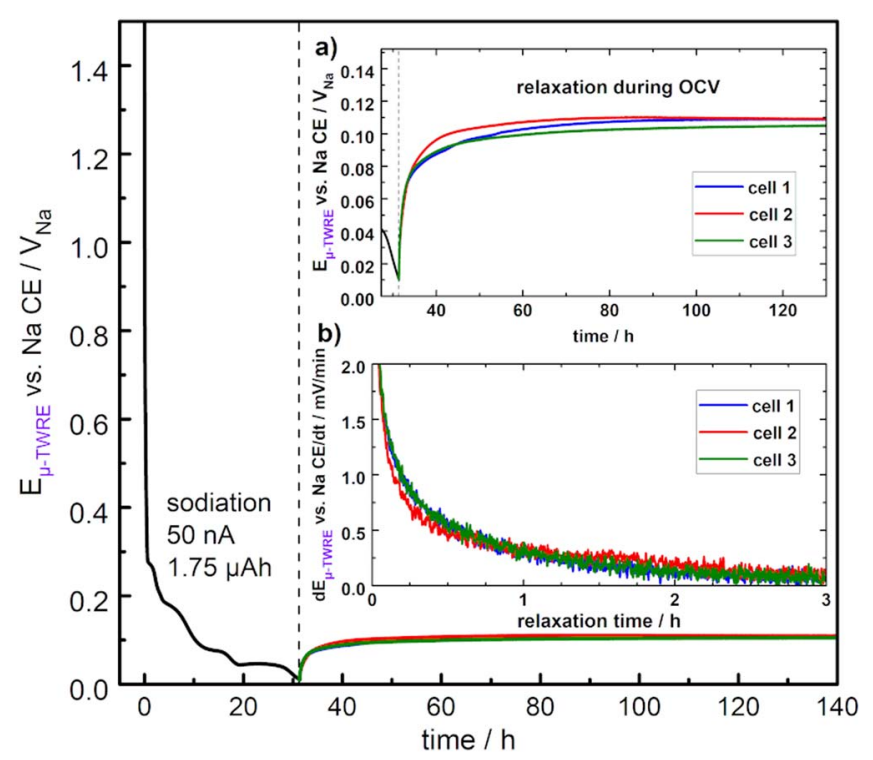

Figure 4. Potential profile during the galvanostatic $(50 \mathrm{nA})$ in situ sodiation of one of the $\mu$-TWRE to a cutoff potential of $10 \mathrm{mV}$ vs. a sodium CE (requiring $\approx 35 \mathrm{~h}$ ), followed by the potential relaxation during the subsequent OCV phase, shown for three independently assembled Swagelok T-cells. a) Magnification of the $\mu$-TWRE potential during the OCV relaxation phase, demonstrating the highly reproducible behavior for three different cells; b) potential drift rate (in $\mathrm{mV} / \mathrm{min}$ ) of these three $\mu$-TWREs during the first $3 \mathrm{~h}$ of the OCV relaxation phase (i.e., after the end of the sodiation procedure).

requiring roughly $22 \mathrm{~h}$ per half-cycle. During sodiation (black line in Figure 3), four potential plateaus can be discerned, whereby the last three plateaus are very distinctly visible during the desodiation half-cycle (red line). Comparing the voltage profile shown in Figure 3 with the combined cycling and X-ray diffraction (XRD) experiments conducted on sputtered tin film electrodes by Ellis et al. ${ }^{33}$ (with an areal sodiation capacity of $\approx 1 \mathrm{mAh} / \mathrm{cm}^{2}$ ), the desodiation plateaus in Figure 3 can most likely be assigned to four different sodium-tin phases, namely $\mathrm{Na}_{15} \mathrm{Sn}_{4}, \mathrm{Na}_{9} \mathrm{Sn}_{4}, \mathrm{NaSn}$, and $\mathrm{NaSn}_{5}$.

In a next step, the stability of the $\mu$-TWRE after sodiation to a cutoff potential of $10 \mathrm{mV}$ vs. $\mathrm{Na}^{+} / \mathrm{Na}$ was evaluated. Figure 4 shows the first galvanostatic $(50 \mathrm{nA})$ sodiation of a $\mu$-TWRE to $10 \mathrm{mV}$ vs. $\mathrm{Na}^{+} / \mathrm{Na}$ (requiring $\approx 35 \mathrm{~h}$ ) and the subsequent relaxation phase over $\approx 100 \mathrm{~h}$ at open circuit voltage (OCV) for three $\mu$-TWRE cells. During sodiation, a total charge of $\approx 1.75 \mu \mathrm{Ah}$ is passed from the sodium WE to the $\mu$-TWRE. Assuming a typical capacity for a SIB cathode electrode of $2 \mathrm{mAh} / \mathrm{cm}^{2}$ (corresponding to $\approx 2 \mathrm{mAh}$ for the here used $11 \mathrm{~mm}$ diameter electrodes), the total charge required for the sodiation of the $\mu$-TWRE would be $<0.1 \%$ of the cathode capacity and can therefore be considered negligible. The magnification of the OCV relaxation phase in inset of Figure 4a clearly shows the highly reproducible potential vs. time profiles for the three $\mu$-TWREs, all relaxing toward a stable potential of $\approx 100-110 \mathrm{mV}$ vs. $\mathrm{Na}^{+} / \mathrm{Na}$. As we want to use the sodiated $\mu$-TWRE to obtain electrode-resolved EIS data down to low frequencies, a sufficiently small $\mu$-TWRE potential drift over the duration of an EIS experiment is required. For a more convenient assessment of the potential drift of the $\mu$-TWRE, the inset of Figure $4 \mathrm{~b}$ shows the time dependence of its potential $\left(\mathrm{dE}_{\mu \text {-TWRE }} / \mathrm{dt}\right)$ over the course of the OCV relaxation phase: approximately $2.5 \mathrm{~h}$ after the sodiation of the $\mu$-TWRE, the potential drift rate decreases to below $\approx 0.1 \mathrm{mV} / \mathrm{min}$, and remains at such low values for another $\approx 100 \mathrm{~h}$ until the end of the experiment (with a total drift of $\approx 2 \mathrm{mV}$ over this period). Considering that the acquisition time for a typical impedance experiment between $100 \mathrm{kHz}$ and $0.1 \mathrm{~Hz}$ is at most $20 \mathrm{~min}$, the maximum potential drift of the $\mu$-TWRE with a drift rate of $\leq 0.1 \mathrm{mV} / \mathrm{min}$ is $\leq 2 \mathrm{mV}$. Therefore, for the potential perturbation amplitude of $20 \mathrm{mV}$ used for our PEIS measurements, the total potential drift of the 

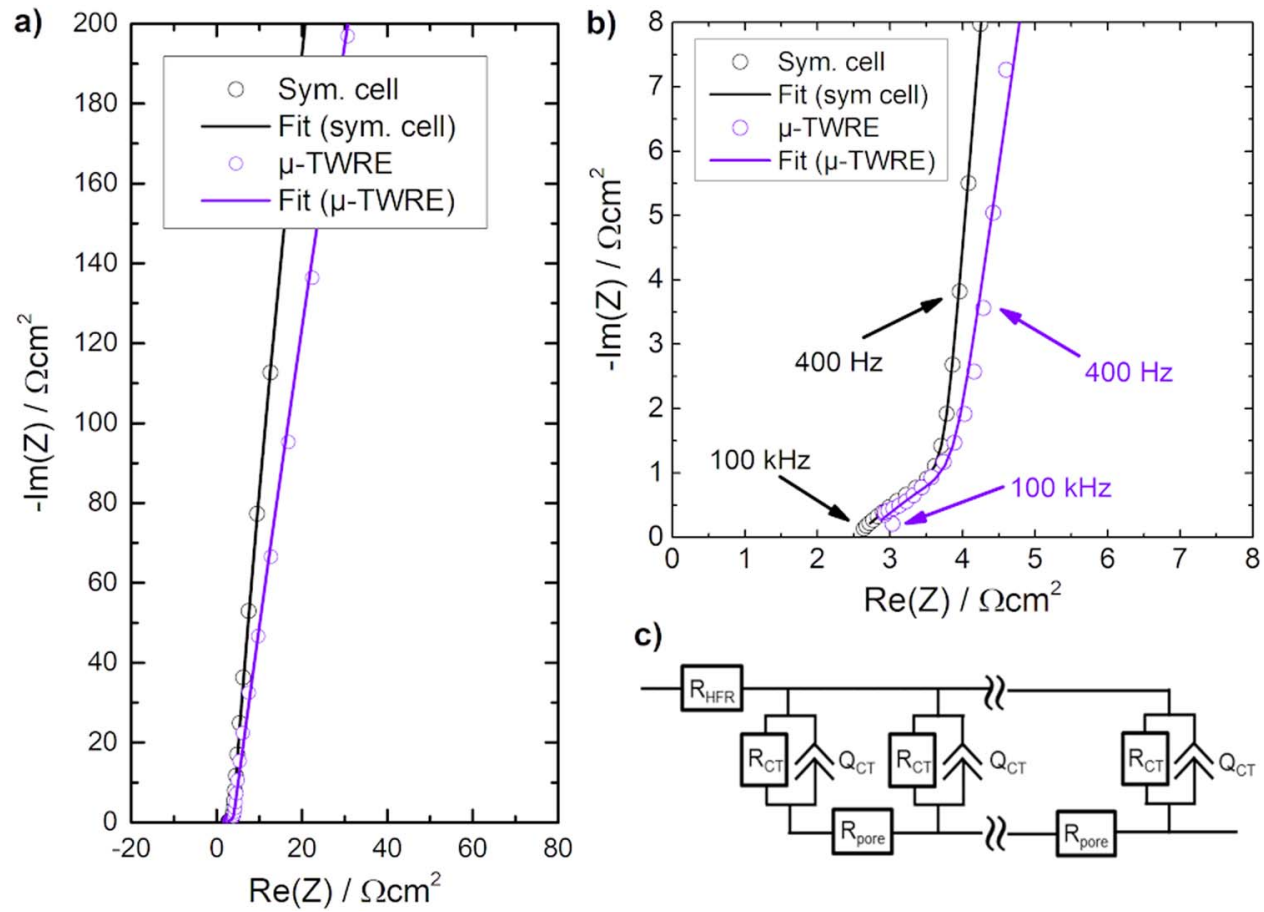

c)

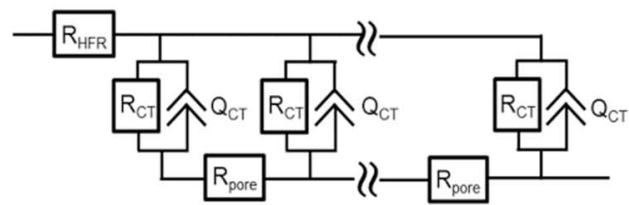

Figure 5. a) Comparison of the Nyquist impedance spectra of the pristine $\mathrm{HC}$ anode in an $\mathrm{HC} / \mathrm{Na}$ half-cell with a $\mu$-TWRE (purple line/symbols) with that of the pristine $\mathrm{HC}$ anode in a symmetrical $\mathrm{HC} / \mathrm{HC}$ cell (black line/symbols), whereby the real and imaginary impedance values of the latter were divided by two in order to represent one single HC electrode. The PEIS data at OCV (taken between $100 \mathrm{kHz}$ and $0.1 \mathrm{~Hz}$ with a perturbation amplitude of $20 \mathrm{mV}$ ) were recorded directly after a $24 \mathrm{~h}$ wetting period. The symbols represent the measured, and the lines the fitted PEIS data (shown between $30 \mathrm{kHz}$ and $\approx 7 \mathrm{~Hz}$ ); b) magnification of the high frequency (HFR) region; c) equivalent circuit used to fit the impedance spectra, consisting of a high-frequency resistance (R $\left.\mathrm{R}_{\mathrm{HFR}}\right)$ and a transmission line model with a parallel $\mathrm{R}_{\mathrm{CT}} / \mathrm{Q}_{\mathrm{CT}}$ element, a negligible electronic resistance rail, and a pore resistance $\left(\mathrm{R}_{\mathrm{pore}}\right)$ that represents the ionic conduction resistance in the electrolyte phase within the HC electrode pores (referred to as mTML circuit; s. Experimental section).

$\mu$-TWRE is only $\approx 10 \%$, satisfying the requirement that the potential drift of the RE must be small with respect to the perturbation amplitude over the duration of the PEIS experiment. This means that after an OCV relaxation time of $\approx 2.5 \mathrm{~h}$, reliable PEIS data can be obtained with our $\mu$-TWRE for the above specified experimental conditions.

Validation of the $\mu$-TWRE impedance data.- - In order to confirm the validity of the impedance response measured with the here developed $\mu$-TWRE, the in situ EIS measurements of the HC anode in an $\mathrm{HC} / \mathrm{Na}$ half-cell are compared with ex situ data collected using an $\mathrm{HC} / \mathrm{HC}$ symmetrical cell. For this purpose, two out of three hard carbon electrodes from the same coating were used to build a symmetrical $\mathrm{HC} / \mathrm{HC}$ T-cell. The third electrode was incorporated into a T-cell equipped with a $\mu$-TWRE (setup depicted in Figure 1a). For each cell, EIS data were acquired at OCV after a $24 \mathrm{~h}$ wetting phase. The resulting Nyquist plots are displayed in Figures $5 \mathrm{a}$ and $5 \mathrm{~b}$, reflecting the so-called blocking conditions (i.e., conditions where the charge transfer resistance $\left(\mathrm{R}_{\mathrm{CT}}\right)$ depicted in the transmission line model shown in Figure $5 c$ is very large), as one would expect for pristine $\mathrm{HC}$ electrodes far above the potential where a charge transfer reaction can occur. The black curves show the impedance response of the symmetrical $\mathrm{HC} / \mathrm{HC}$ cell, whereby the real and imaginary values were divided by 2 in order to represent one of the two nominally identical hard carbon electrodes. The purple lines show the EIS data of the $\mathrm{HC}$ electrode collected from an $\mathrm{HC} / \mathrm{Na}$ half-cell equipped with the $\mu$ TWRE. While the high-frequency intercepts for the data sets shown in Figures $5 \mathrm{a}$ and $5 \mathrm{~b}$ is very similar, as one would expect, one needs to note that differences up to $\approx 1 \Omega \mathrm{cm}^{2}$ have been observed in repeat experiments with different cells, which originates from slightly different compressions of the two easily compressible $250 \mu \mathrm{m}$ thick glass fiber separators that is due to the slight variations in the compression of the T-cells, which are equipped with a compression spring. ${ }^{9}$ Furthermore, the impedance spectrum of the HC/Na half-cell with the $\mu$-TWRE displays a downward pointing bend at frequencies above $\approx 30 \mathrm{kHz}$ (s.
Figure 5b), which is a well-known artefact of high impedance REs, that was also observed before. ${ }^{14,34}$ Therefore, only impedance values at frequencies below $\approx 30 \mathrm{kHz}$ should be taken into account when using the $\mu$-TWRE.

The impedance spectra feature a $45^{\circ}$-line at high frequencies, originating from the ionic conduction resistance in the electrolyte phase within the porous electrode $\left(\mathrm{R}_{\text {pore }}\right)$ that is nicely visible under blocking conditions; at lower frequencies, this transitions into an almost purely capacitive behavior (i.e., a nearly vertical line in the Nyquist plot). As outlined by Landesfeind et al., ${ }^{14}$ the impedance responses shown in Figures $5 \mathrm{a}$ and $5 \mathrm{~b}$ can be fitted with the simple transmission line model depicted in Figure 5c, consisting of an ionic conduction rail represented by $R_{\text {pore }}$, of parallel circuit elements of a charge transfer resistance $\left(\mathrm{R}_{\mathrm{CT}}\right)$ and a constant phase element $\left(\mathrm{Q}_{\mathrm{CT}}\right)$ that represents the double-layer capacitance, and of an electronic conduction rail with a negligible electronic resistance in the case of the highly conductive hard carbon electrode (referred to here as MTLM circuit). Fitting the data in Figures $5 \mathrm{a}$ and $5 \mathrm{~b}$ to the circuit in Figure $5 \mathrm{c}$, the obtained $\mathrm{R}_{\text {pore }}$ values are $4.1 \pm 0.3 \Omega \mathrm{cm}^{2}$ for a single $\mathrm{HC}$ electrode in the symmetrical $\mathrm{HC} / \mathrm{HC}$ cell (based on two repeat experiments) and $4.5 \pm 0.3$ $\Omega \mathrm{cm}^{2}$ for the HC electrode in the HC/Na half-cell with the $\mu$-TWRE (based on three repeat experiments). Therefore, within the error of measurement, the impedance analysis for the $\mathrm{HC} / \mathrm{HC}$ symmetrical cells and the HC/Na half-cells with the $\mu$-TWRE agrees very well, and thus validates the accuracy of the $\mu$-TWRE approach (similarly good agreement was observed previously for a lithiated gold wire $\mu$ $\left.\mathrm{RE}^{14}\right)$. From the pore resistances, the tortuosities of the electrodes can be calculated: ${ }^{35}$ taking into account an electrolyte conductivity of $8.2 \mathrm{mS} / \mathrm{cm}$ (at $25^{\circ} \mathrm{C}$ ), an electrode thickness of $\approx 44 \mu \mathrm{m}$, a porosity of $60 \%$, and an electrode area of $0.95 \mathrm{~cm}^{2}$, this equates to electrode tortuosities of $4.4 \pm 0.3$ and $4.8 \pm 0.3$ for the $\mathrm{HC} / \mathrm{HC}$ symmetrical cell and the $\mathrm{HC} / \mathrm{Na}$ half-cell measurements, respectively. In comparison, tortuosities measured for flake-like graphite electrodes using the same technique were found to be around $5 .^{35}$ 
Hard carbon impedance evolution during cycling.-As already described above, a major advantage of the in situ impedance measurement method with a $\mu$-TWRE for SIBs is the possibility to very easily monitor the impedance of an individual electrode (in the present case the $\mathrm{HC}$ electrode) during (long-term) cycling of a cell. In the literature, impedance data on sodiated hard carbon electrodes are quite rare. If provided, the measured impedances are often not normalized to the electrode area, ${ }^{29,36-38}$ which makes a quantitative comparison between different studies difficult. More problematic, however, is that most studies simply monitor the change in cell impedance and ascribe this to a change in the hard carbon impedance,,$^{29,36-40}$ i.e., neglecting possible changes in the impedance of the $\mathrm{CE}$, which in most of these studies was sodium metal. For example, Väli et al. ${ }^{39}$ present impedance data between $300 \mathrm{kHz}$ and $10 \mathrm{mHz}$ of a glucose-derived hydrothermal hard carbon in an HC/Na half-cell in EC/DMC + $1 \mathrm{M}$ $\mathrm{NaPF}_{6}$ electrolyte, measured after cycling to different cell potentials $(1.0,0.6,0.37$, and $0.04 \mathrm{~V})$, analyzing the change in cell impedance, i.e., the sum of the impedance of the hard carbon WE and of the sodium CE. Since the surface area of the sodium counter electrode is likely to change substantially during cycling, especially during the half-cycles where sodium plating occurs, the impedance of the sodium electrode is expected to also change over the course of cycling; this is well known for lithium metal electrodes, ${ }^{41,42}$ where the impedance change of a graphite electrode in graphite/Li half-cell impedance measurements is often mistakenly ascribed to the change in the impedance of the graphite electrode. ${ }^{43}$ There is clear evidence in the literature that the same uncertainties are present in the case of impedance measurements of cells with a sodium metal electrode, particularly as the charge transfer resistance of a typical sodium metal electrode is rather large (several hundreds of $\Omega \mathrm{cm}^{2}$, with the exact value depending on the sodium metal roughness $\mathrm{s}^{44,45}$ ). Moreover, in a recent study, Dugas et al..$^{45}$ point out that the SEI formed on a sodium metal electrode is not stable and that therefore also the impedance of the $\mathrm{Na}$ electrode changes drastically over time, which was measured in an $\mathrm{Na} / \mathrm{Na}$ symmetrical cell in EC/DMC + $(50 \mathrm{v} \% / 50 \mathrm{v} \%)+1 \mathrm{M} \mathrm{NaPF}_{6}$ over $290 \mathrm{~h}$. Here, the charge transfer resistance roughly doubled from $\approx 150 \Omega \mathrm{cm}^{2}$ to $\approx 300 \Omega \mathrm{cm} .{ }^{2}$ Due to the fact that the impedance of the sodium counter electrode cannot be deconvoluted from the overall cell impedance, no precise information on the evolution of the hard carbon impedance can be gained from the overall impedance of $\mathrm{HC} / \mathrm{Na}$ half-cells, unless the hard carbon impedance would be significantly larger than the estimated several hundreds of $\Omega \mathrm{cm}^{2}$ expected for the $\mathrm{Na}$ electrode.

As already discussed above, one way to eliminate the impedance contribution from the sodium metal CE would be the use of symmetrical cells. Unfortunately, hardly any published study determines the impedance of the hard carbon electrode with symmetrical cells or even with a reference electrode. An exception is a study by Ding et al., ${ }^{46}$ who use the symmetrical cell approach in order to deconvolute the contributions from the sodium metal CE. Here, they investigate the electrochemical performance of a hard carbon anode for ionicliquid based SIBs in a temperature range of $10-90^{\circ} \mathrm{C}$ using $\mathrm{Na} / \mathrm{Na}$ and $\mathrm{HC} / \mathrm{HC}$ symmetrical cells. As a conclusion, they stress that the $\mathrm{R}_{\mathrm{CT}}$ value for the Na electrode is much larger than that for the $\mathrm{HC}$ electrode, which again demonstrates that overall cell impedance data on SIB half-cells can easily be misinterpreted if the sodium metal impedance contribution is not taken into account.

To the best of our knowledge, there are no data on the impedance evolution of a hard carbon anode over extended cycling of an $\mathrm{HC} / \mathrm{Na}$ half-cell, neither measured in symmetrical cells nor employing a $\mu$-RE. Figure 6a shows the hard carbon impedance spectra of a hard carbon electrode cycled vs. sodium metal (as shown in Figure 1a). PEIS was measured during cycling at a cell potential of $100 \mathrm{mV}_{\text {cell }}$ during the sodiation cycle after an OCV relaxation phase of $30 \mathrm{~min}$ (measured at OCV). Depicted are the EIS spectra recorded during cycle 1 (purple symbols) and cycle 2 (cyan symbols). Both hard carbon impedance spectra feature a large semi-circle at low frequencies, with an apex frequency of $\approx 25 \mathrm{~Hz}$, presumably representing the charge transfer resistance of the hard carbon anode, as well as a short $45^{\circ}$-line at high frequencies, which reflects $R_{\text {pore }}$. The impedance spectra were fitted
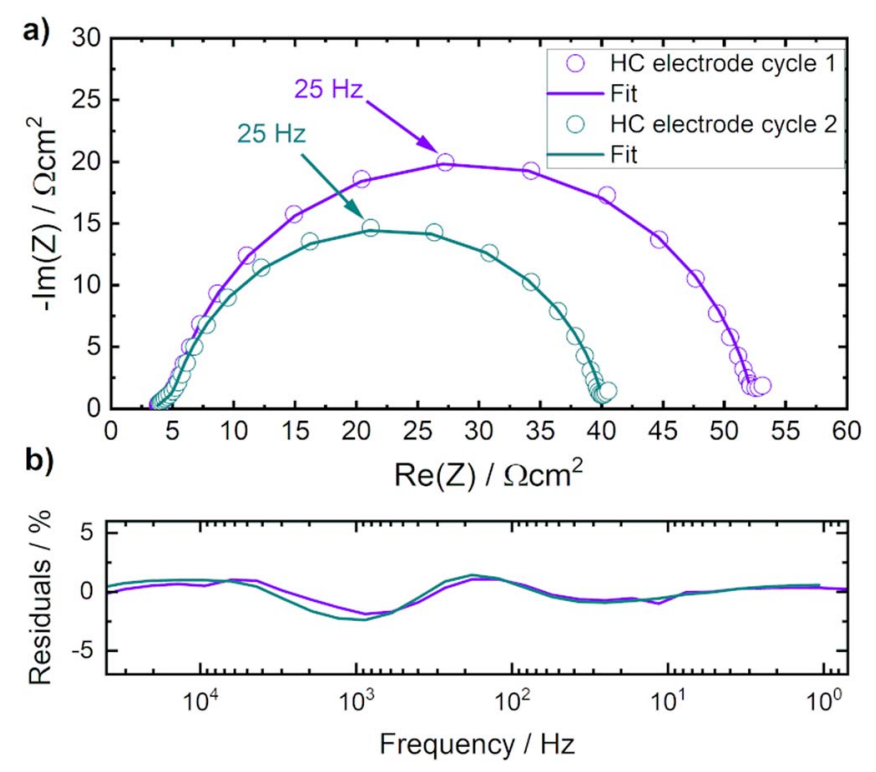

Figure 6. a) Nyquist impedance plot of the hard carbon electrode impedance measured in an $\mathrm{HC} / \mathrm{Na}$ half-cell using the $\mu$-TWRE (for the cell setup s. Figure 1a) during cycling at rate of $0.1 \mathrm{C}$ at $25^{\circ} \mathrm{C}$ for the first cycle (purple line/symbols) and for the second cycle (cyan line/symbols). For the impedance measurements, the cell was cycled to a cell potential of $100 \mathrm{mV}_{\text {cell }}$ during the sodiation cycle, then held at OCV for $30 \mathrm{~min}$, after which time a PEIS was acquired at $\mathrm{OCV}$ between $100 \mathrm{kHz}$ and $0.1 \mathrm{~Hz}$ and with an amplitude of $20 \mathrm{mV}$. The impedance data are depicted by symbols and the fit to the equivalent circuit shown in Figure $5 \mathrm{c}$ is given by the lines (for fitting parameter, s. Table I); b) residuals between the impedance data and the equivalent circuit fit, demonstrating the good description of the impedance data by the simple equivalent circuit depicted in Figure 5c.

using the equivalent circuit shown in Figure $5 c$, whereby the ionic resistance $R_{\text {pore }}$ was fixed to the value of $4.5 \Omega \mathrm{cm}^{2}$ that was determined from the fit under blocking conditions (s. discussion of Figure 5); to obtain a stable fit, the electronic resistance of the electronic rail (s. Figure 5c) was set to a very small value of $0.001 \Omega \mathrm{cm}^{2}$, which essentially means that the resistance of the electronic rail is negligible. The resulting fit is shown by the solid lines in Figure 6a and the error between the fit and the data is depicted in Figure 6b, demonstrating that the simple equivalent circuit shown in Figure $5 \mathrm{c}$ with only one $\mathrm{R}_{\mathrm{CT}} / \mathrm{Q}_{\mathrm{CT}}$ element is sufficient to describe the impedance response of the HC electrode. The resulting fitting parameters to describe the hard carbon electrode impedance in the first and second cycle are summarized in Table I. For the obtained $\alpha_{\mathrm{CT}}$ values that are reasonably close to 1 , the magnitudes of the constant phase elements $\left(\mathrm{Q}_{\mathrm{CT}}\right)$ can be approximated with a capacitance, which in turn can be normalized by the actual surface area of the hard carbon electrodes of $\approx 150 \mathrm{~cm}^{2}{ }_{\mathrm{HC}} / \mathrm{cm}^{2}$ (from $\approx 3 \mathrm{mg}_{\mathrm{HC}} / \mathrm{cm}^{2}$ loading and $\approx 5 \mathrm{~m}^{2} \mathrm{HC}_{\mathrm{HC}} \mathrm{BET}$ ), yielding a surface area normalized capacitance of $\approx 1.7 \mu \mathrm{F} / \mathrm{cm}^{2}{ }_{\mathrm{HC}}$. This is consistent

\footnotetext{
Table I. Summary of the fitting parameter and the obtained parameter values for the hard carbon impedance spectra shown in Figure 6a, using the equivalent circuit depicted in Figure 5c. Here, $\mathbf{R}_{\mathrm{HFR}}$ is the high frequency resistance, $\mathbf{R}_{\mathrm{CT}}$ is the charge transfer resistance of the hard carbon electrode, $Q_{\mathrm{CT}}$ is the constant phase magnitude, and $\alpha_{C T}$ is the constant phase exponent.
}

\begin{tabular}{llllll} 
& \multicolumn{2}{c}{ Cycle 1 } & & \multicolumn{2}{c}{ Cycle 2 } \\
\cline { 2 - 3 } parameter & value & error $/ \%$ & & value & error/\% \\
\hline $\mathrm{R}_{\mathrm{HFR}} / \Omega \mathrm{cm}^{2}$ & 3.4 & 2.2 & & 3.3 & 2.3 \\
$\mathrm{R}_{\mathrm{CT}} / \Omega \mathrm{cm}^{2}$ & 47.6 & 0.3 & & 35.3 & 0.5 \\
$\mathrm{Q}_{\mathrm{CT}} / \mathrm{mF} \cdot \mathrm{s}^{\left(\alpha_{\mathrm{CT}}-1\right)} / \mathrm{cm}^{2}$ & 0.25 & 1.9 & & 0.26 & 2.8 \\
$\mathrm{a}_{\mathrm{CT}} /$ & 0.9 & 0.4 & & 0.9 & 0.6
\end{tabular}


with a typical double-layer capacitance in aprotic electrolytes ${ }^{47}$ and therefore confirms that the semi-circle feature in Figure 6a represents the charge-transfer resistance of the hard carbon electrode.

The charge transfer resistance $\mathrm{R}_{\mathrm{CT}}$ of the hard carbon anode in the first cycle is on the order of $50 \Omega \mathrm{cm}^{2}$ (s. Table I), i.e., much smaller than the above estimated charge transfer resistance of a typical sodium metal electrode. Thus, its value could not be obtained from the overall $\mathrm{HC} / \mathrm{Na}$ cell impedance without the use of a reference electrode. The hard carbon $R_{C T}$ also significantly decreases from cycle 1 to cycle 2 . Other carbon-based intercalation materials, such as graphite, do not exhibit a decreasing charge transfer resistance in the first two cycles, but rather show a monotonously increasing anode impedance with time, ${ }^{9,15}$ usually explained by SEI growth and a subsequent increase in SEI resistance. A plausible reason for the decrease in $R_{C T}$ for the hard carbon anode in an SIB could be that the surface area of the hard carbon electrode is increasing during the first cycle(s), owing perhaps to the opening of pores or other as yet unknown phenomena.

Figure 7 a shows the voltage profiles for cycle 1,2, and 52 of a hard carbon anode cycled at $0.1 \mathrm{C}$ and $25^{\circ} \mathrm{C}$ vs. sodium metal in an $\mathrm{HC} / \mathrm{Na}$ half-cell with a $\mu$-TWRE, with the inset depicting the evolution of the specific desodiation capacity and the coulombic efficiency vs. cycle number. The hard carbon cell exhibits a high first-cycle coulombic efficiency of $\approx 92 \%$, which is close to values that have been reported for this type of HC. ${ }^{44}$ After the second cycle in which a coulombic efficiency of $>99.5 \%$ has been reached, the capacity fading of the hard carbon electrode is minor, retaining a specific reversible capacity of $265 \mathrm{mAh} / \mathrm{g}_{\mathrm{HC}}$ or $\approx 94 \%$ after 52 cycles.

Figure $7 \mathrm{~b}$ shows Nyquist impedance plots, each measured during sodiation at a cell potential of $100 \mathrm{mV}$ vs. Na CE and a $30 \mathrm{~min}$ relaxation phase at OCV during cycle 1,2 , and afterwards during every $10^{\text {th }}$ cycle between $100 \mathrm{kHz}$ and $10 \mathrm{mHz}$. As already explained for the impedance spectra of cycle 1 and 2 in detail above, within the first two cycles, two regions can be distinguished within the impedance spectra. A large semi-circle at mid and low frequencies, which we attribute to a charge transfer resistance $\left(\mathrm{R}_{\mathrm{CT}}, \approx 48 \Omega \mathrm{cm}^{2}\right.$ for cycle 1 and $\approx 36 \Omega \mathrm{cm}^{2}$ for cycle 2 ), and a short line with a $45^{\circ}$-slope at high frequencies (visible in a magnification of Figure 6a, not shown) originating from a pore resistance $\left(\mathrm{R}_{\text {pore }}\right)$, which we also identified in the impedance spectrum of the blocking hard carbon electrode $(0 \%$ SOC) in Figure 5. This pore resistance at high frequencies and the semi-circle at mid frequencies is also visible during all other cycles. However, roughly starting at cycle 22, a second semi-circle at higher frequencies compared to the first semi-circle is evolving and growing in magnitude with increasing cycle number, which is most apparent in cycle 52 . This second semi-circle might be due to the SEI resistance that is hidden underneath the large semi-circle during the first cycles. With ongoing cycling, the SEI resistance is likely to increase which could be the reason that this process becomes more and more visible as a second semi-circle for higher cycle numbers.

The total magnitude of the hard carbon electrode impedance, which we define as the difference of the real part of the low frequency resistance at $0.1 \mathrm{~Hz}\left(\mathrm{R}_{\mathrm{LFR}}\right)$ and the real part of the high frequency resistance at $30 \mathrm{kHz}\left(\mathrm{R}_{\mathrm{HFR}}\right)$, is plotted in Figure $7 \mathrm{~b}$ (s. inset). As already mentioned above, Figure $7 \mathrm{~b}$ shows that the total, real part of the electrode resistance first decreases during initial cycling (at least in the second cycle, however, most likely within the first couple of cycles) and afterwards slowly increases. Taking into account the processes that we assigned to the features in the impedance spectra above, we speculate that the increase in electrode impedance for longer cycling ( $>$ cycle 22 ), is related to aging effects of the electrode, most likely due to a growth of the SEI. This hypothesis is supported by the fact that the diameter of the second, larger semi-circle stays roughly constant from cycle 22 and the increase of the total resistance seems to originate from the second, smaller semi-circle that we attributed to an SEI resistance.

\section{Conclusions}

In this work, we introduce a new method that enables in situ impedance measurements in sodium-ion battery cells, which al-
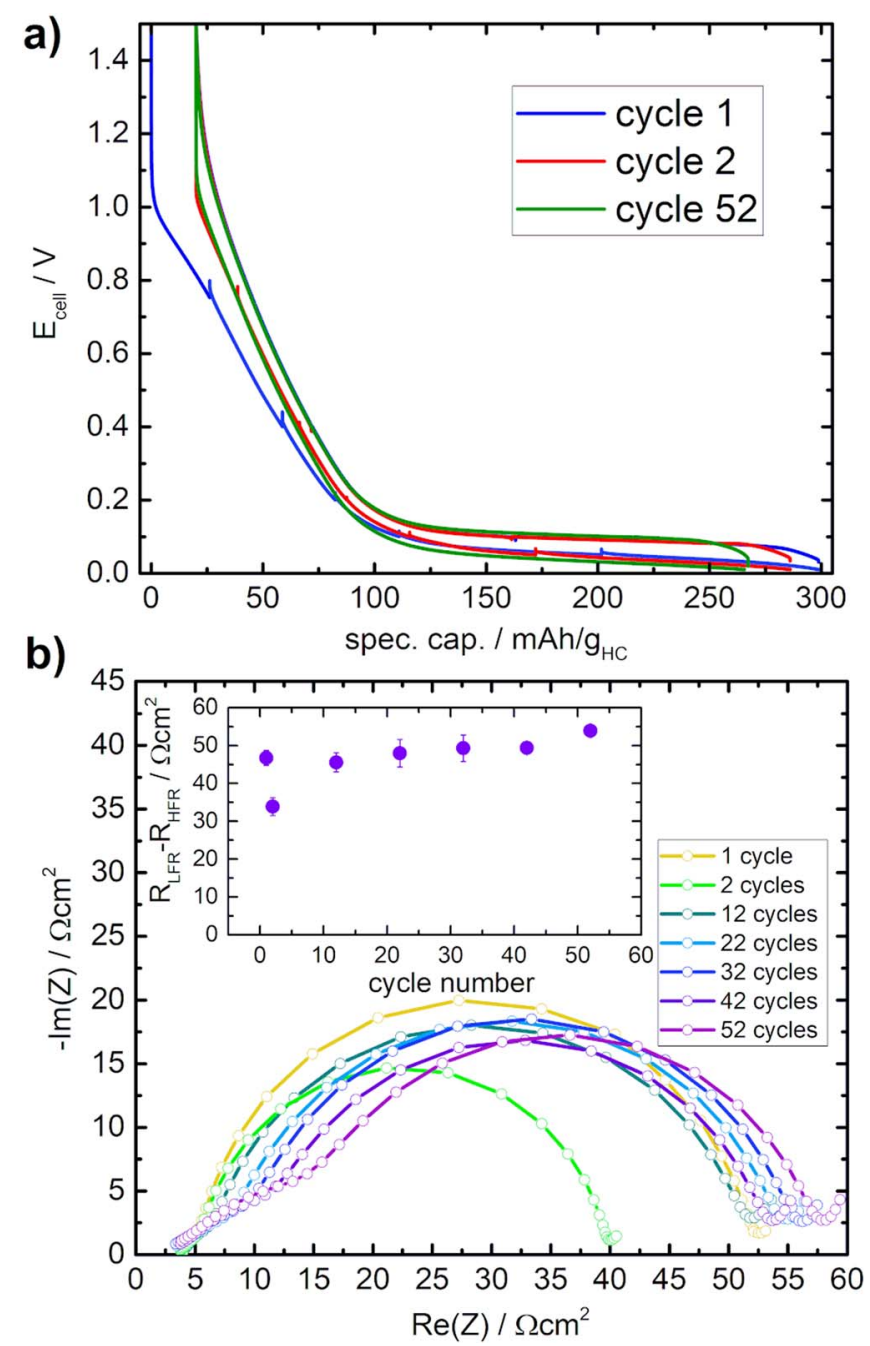

Figure 7. a) Voltage profiles of cycle 1, 2, and 52 for the (de)-sodiation of a hard carbon anode cycled between 1.5 and $0.01 \mathrm{~V}_{\text {cell }}$. The inset shows the specific desodiation capacity and the coulombic efficiency vs. cycle number; $b$ ) Nyquist plot of the impedance response of a hard carbon electrode in an $\mathrm{HC} / \mathrm{Na}$ half-cell obtained with a sodiated $\mu$-TWRE and measured during the first, second, and thereafter every $10^{\text {th }}$ sodiation cycle at a potential of $100 \mathrm{mV}_{\text {cell }}$ (data for cycle 1 and 2 are the same as in Figure 6). The inset depicts the overall electrode impedance obtained by subtracting the high-frequency resistance recorded at $30 \mathrm{kHz}\left(\mathrm{R}_{\mathrm{HFR}}\right)$ from the low-frequency resistance recorded at $0.1 \mathrm{~Hz}$ $\left(\mathrm{R}_{\mathrm{LFR}}\right)$. Conditions: $25^{\circ} \mathrm{C}, \mathrm{EC} / \mathrm{DEC}(50 \mathrm{v} \% / 50 \mathrm{v} \%)+1 \mathrm{M} \mathrm{NaPF}_{6}$ electrolyte, cycling at a rate of $0.1 \mathrm{C}$, PEIS with $20 \mathrm{mV}$ amplitude after an OCV phase of $30 \mathrm{~min}$, frequency range $100 \mathrm{kHz}-0.1 \mathrm{~Hz}$

lows for separating single-electrode contributions to the overall cell impedance. The newly developed technique is based on a $\mu$-RE consisting of $\mathrm{a} \approx 100 \mu \mathrm{m}$ thick tinned copper wire with a polyurethane insulation, referred to as tin-wire micro-reference electrode ( $\mu$-TWRE) that can be easily incorporated into a Swagelok type T-cell. By in situ sodiating the tip of the tinned wire from a sodium source within the cell, e.g., from a sodium metal counter electrode or a sodium containing cathode active material, it is possible to alloy sodium with tin, yielding Na-Sn-phases that exhibit a reference electrode potential, which is stable enough in order to perform high-quality impedance measurements. The validity of the data obtained from the $\mu$-TWRE was evaluated by comparing them to measurements performed in symmetrical cells, which were in very good agreement.

The use of this newly developed $\mu$-RE makes it possible to easily monitor the impedance evolution of an individual electrode in sodiumion battery cells over extended cycling, thereby saving experimental effort compared to the use of symmetrical cells and eliminating 
possible artefacts introduced by cell assembly and disassembly required for symmetrical cell measurements. As a first application, we measured the impedance of a hard carbon anode cycled vs. a sodium metal counter electrode at a rate of $0.1 \mathrm{C}$ over 50 cycles. Interestingly, the impedance of the electrode decreases during the first cycles, a phenomenon not known for the intercalation of lithium in graphite, and afterwards increases steadily. We assume that the decreasing impedance might stem from a surface area increase of the active material particles during SEI formation. The herein presented $\mu$-TWRE based EIS method could be used in future studies to characterize novel anode and cathode materials for sodium-ion batteries over long-term cycling and to identify cross-talk phenomena between working and counter electrode.

\section{Acknowledgment}

We gratefully acknowledge the funding by the BMBF (Federal Ministry of Education and Research, Germany) for its financial support under the auspices of the ExZellTUM II project, grant number 03XP0081. The authors would like to thank Tim-Patrick Fellinger for providing the hard carbon samples from Kuraray as well as Robert Morasch for his development of a procedure which allowed to obtain EIS data with capacitively strongly imbalanced electrodes and Bharat Suthar for his advice on EIS fitting.

\section{ORCID}

Fabian Linsenmann (D) https://orcid.org/0000-0001-8788-2584 Daniel Pritzl (D) https://orcid.org/0000-0002-9029-107X

\section{References}

1. McKinsey, "Electric Vehicle Index 2019," can be found under https://www.mckinsey de/branchen/automobil-zulieferer/electric-vehicle-index, accessed on 09/04/2019.

2. VW, "Volkswagen plans 22 million electric vehicles in ten years," can be found under https://www.volkswagen-newsroom.com/en/press-releases/volkswagen-plans-22million-electric-vehicles-in-ten-years-4750, accessed on 09/04/2019.

3. D. L. Anderson, Theory of the Earth, Blackwell Scientific Publications 1989.

4. L. Chen, M. Fiore, J. E. Wang, R. Ruffo, D.-K. Kim, and G. Longoni, Adv. Sustain. Syst., 1 (2018).

5. B. L. Ellis and L. F. Nazar, Curr. Opin. Solid State Mater. Sci., 16, 168 (2012).

6. K. Kubota and S. Komaba, J. Electrochem. Soc., 162, A2538 (2015).

7. N. Yabuuchi, K. Kubota, M. Dahbi, and S. Komaba, Chem. Rev., 114, 11636 (2014).

8. M. I. Jamesh and A. S. Prakash, J. Power Sources, 378, 268 (2018).

9. S. Solchenbach, D. Pritzl, E. J. Y. Kong, J. Landesfeind, and H. A. Gasteiger, J. Electrochem. Soc., 163, A2265 (2016).

10. J. C. Burns, N. N. Sinha, G. Jain, H. Ye, C. M. VanElzen, W. M. Lamanna, A. Xiao, E. Scott, J. Choi, and J. R. Dahn, J. Electrochem. Soc., 159, A1095 (2012).
11. M. Klett, J. A. Gilbert, S. E. Trask, B. J. Polzin, A. N. Jansen, D. W. Dees, and D. P. Abraham, J. Electrochem. Soc., 163, A875 (2016).

12. N. Ogihara, S. Kawauchi, C. Okuda, Y. Itou, Y. Takeuchi, and Y. Ukyo, J. Electrochem. Soc., 159 (2012).

13. R. Petibon, C. P. Aiken, N. N. Sinha, J. C. Burns, H. Ye, C. M. VanElzen, G. Jain, S. Trussler, and J. R. Dahn, J. Electrochem. Soc., 160, A117 (2013).

14. J. Landesfeind, D. Pritzl, and H. A. Gasteiger, J. Electrochem. Soc., 164, A1773 (2017).

15. D. Pritzl, S. Solchenbach, M. Wetjen, and H. A. Gasteiger, J. Electrochem. Soc., 164, A2625 (2017).

16. M. Ender, J. Illig, and E. Ivers-Tiffée, J. Electrochem. Soc., 164, A71 (2017).

17. J. Costard, M. Ender, and M. Weiss, J. Electrochem. Soc., 164, 80 (2017).

18. D. P. Abraham, S. D. Poppen, A. N. Jansen, J. Liu, and D. W. Dees, Electrochim. Acta, 49, 4763 (2004).

19. J. C. Burns, L. J. Krause, D.-B. Le, L. D. Jensen, A. J. Smith, D. Xiong, and J. R. Dahn, J. Electrochem. Soc., 158, A1417 (2011).

20. R. Petibon, N. N. Sinha, J. C. Burns, C. P. Aiken, H. Ye, C. M. Vanelzen, G. Jain, S. Trussler, and J. R. Dahn, J. Power Sources, 251, 187 (2014).

21. R. Petibon, E. C. Henry, J. C. Burns, N. N. Sinha, and J. R. Dahn, J. Electrochem. Soc., 161, A66 (2014).

22. C. H. Chen, J. Liu, and K. Amine, J. Power Sources, 96, 321 (2001).

23. M. Ender, E. Ivers-Tiffé, and A. Weber, J. Electrochem. Soc., 159, 128 (2012).

24. M. Dollé, F. Orsini, A. S. Gozdz, and J.-M. Tarascon, J. Electrochem. Soc., 148, A851 (2002).

25. D. Pritzl, J. Landesfeind, S. Solchenbach, and H. A. Gasteiger, J. Electrochem. Soc., 165, A2145 (2018).

26. A. D. Pelton, J. Phase Equilibria, 7, 228 (1986).

27. J. I. Kroschwitz and A. Seidel, Kirk-Othmer Encyclopedia of Chemical Technology, Wiley, 2006.

28. H. Hou, X. Qiu, W. Wei, Y. Zhang, and X. Ji, Adv. Energy Mater., 7, 1 (2017).

29. C. Bommier, D. Leonard, Z. Jian, W. F. Stickle, P. A. Greaney, and X. Ji, Adv. Mater. Interfaces, 3(19), 1600449 (2016).

30. S. Komaba, W. Murata, T. Ishikawa, N. Yabuuchi, T. Ozeki, T. Nakayama, A. Ogata, K. Gotoh, and K. Fujiwara, Adv. Funct. Mater., 21, 3859 (2011).

31. E. Irisarri, A. Ponrouch, and M. R. Palacin, J. Electrochem. Soc., 162, A2476 (2015).

32. R. Morasch, B. Suthar, and H. A. Gasteiger, to be submitted.

33. L. D. Ellis, T. D. Hatchard, and M. N. Obrovac, J. Electrochem. Soc., 159, A1801 (2012).

34. S. Solchenbach, PhD Thesis, Technical University of Munich, 2018.

35. J. Landesfeind, J. Hattendorff, A. Ehrl, W. A. Wall, and H. A. Gasteiger, J. Electrochem. Soc., 163, A1373 (2016).

36. C. Bommier, W. Luo, W. Y. Gao, A. Greaney, S. Ma, and X. Ji, Carbon N. Y., 76, 165 (2014).

37. W. Lv, F. Wen, J. Xiang, J. Zhao, L. Li, L. Wang, Z. Liu, and Y. Tian, Electrochim. Acta, 176, 533 (2015).

38. A. Ponrouch, A. R. Goñi, and M. R. Palacín, Electrochem. Commun., 27, 85 (2013).

39. R. Väli, A. Jänes, T. Thomberg, and E. Lust, Electrochim. Acta, 253, 536 (2017).

40. R. Väli, A. Jänes, T. Thomberg, and E. Lust, J. Electrochem. Soc., 163, A1619 (2016).

41. D. Aurbach, E. Zinigrad, Y. Cohen, and H. Teller, Solid State Ionics, 148, 405 (2002).

42. G. A. Umeda, E. Menke, M. Richard, K. L. Stamm, and B. Dunn, Journal of Materials Chemistry, 4, 1593 (2011).

43. J. Y. Song, H. H. Lee, Y. Y. Wang, and C. C. Wan, J. Power Sources, 111, 255 (2002).

44. M. Dahbi, T. Nakano, N. Yabuuchi, S. Fujimura, K. Chihara, K. Kubota, J. Y. Son, Y. T. Cui, H. Oji, and S. Komaba, ChemElectroChem, 3, 1856 (2016).

45. R. Dugas, A. Ponrouch, G. Gachot, R. David, M. R. Palacin, and J. M. Tarascon, J. Electrochem. Soc., 163, A2333 (2016).

46. C. Ding, T. Nohira, R. Hagiwara, A. Fukunaga, S. Sakai, and K. Nitta, Electrochim. Acta, 176, 344 (2015).

47. D. Pritz, A. E. Bumberger, M. Wetjen, J. Landesfeind, S. Solchenbach, and H. A. Gasteiger, J. Electrochem. Soc., 166, A582 (2019). 